\title{
Structural Abnormalities of the Central Retina in Neurofibromatosis Type 2
}

\author{
Beatrice Emmanouil ${ }^{a, b}$ Martin Wasik ${ }^{a, c}$ Peter Charbel Issa ${ }^{c, d}$ \\ Dorothy Halliday ${ }^{a}$ Allyson Parry ${ }^{a}$ Srilakshmi M. Sharma ${ }^{\text {c, d }}$
}

aNeurofibromatosis Type 2 Unit, Department of Neurosciences, Oxford University Hospitals NHS Foundation Trust, Oxford, UK; 'b Department of Psychology, Health and Professional Development, Oxford Brookes University, Oxford, UK; ' ${ }^{c}$ xford Eye Hospital, Oxford University Hospitals NHS Foundation Trust, Oxford, UK; dNuffield Laboratory of Ophthalmology, Nuffield Department of Clinical Neurosciences, University of Oxford, Oxford, UK

\section{Keywords}

Spectral domain optical coherence tomography .

Neurofibromatosis type $2 \cdot$ Retinal tufts $\cdot$ Retinal

hamartoma $\cdot$ Genetic severity

\begin{abstract}
Introduction: This case-control study seeks to systematically characterize the central retinal findings in a large cohort of patients with neurofibromatosis type 2 (NF2) using spectral domain optical coherence tomography (SD-OCT) as well as the examination of the potential use of this technique as a diagnostic tool in NF2. Methods: Fifty-four patients with an NF2 diagnosis seen in a quaternary national service were age- and gender-matched to 55 controls from the normal population. Two masked assessors categorized SD-OCT images using predefined abnormalities: retinal tufts, epiretinal membrane (ERM) appearance, retinal hamartoma, and foveal contour. Specificity, sensitivity, and positive and negative predictive values were calculated for each retinal abnormality. Trends of retinal abnormalities with NF2 genetic severity groups (1. tissue mosaic; 2A. mild classic; 2B. moderate classic; and 3. severe) were investigated. Results: We found retinal abnormalities in 26 patients with NF2 (48\%) and 2 control
\end{abstract}

patients (4\%); retinal tufts were the most common abnormality therein (43\%) and were not seen in controls. The specificity and sensitivity of the graded abnormalities on OCT scans in NF2 were $96 \%$ and $48 \%$, respectively, with a positive predictive value of $93 \%$. In our cohort, retinal tufts had a specificity of $100 \%$, a sensitivity of $43 \%$, and a positive predictive value of $100 \%$. Retinal hamartomas were seen only in NF2 patients (35\% sensitivity and $100 \%$ specificity). ERMs had $96 \%$ specificity and $13 \%$ sensitivity. The proportion of patients with retinal abnormalities increased statistically significantly with NF2 genetic severity; all patients within the 3 . severe genetic severity had an abnormal SD-OCT. Discussion/Conclusion: We present a systematic study of central retinal abnormalities in an NF2 population as seen on SDOCT imaging. Our results show a high frequency of retinal abnormalities that are readily detected by SD-OCT imaging. The presence of retinal tufts may be a novel marker of NF2 with both high specificity and a positive predictive value for NF2, compared to other well-known ocular features of NF2, and may have a place in the NF2 diagnostic criteria.

(c) 2021 The Author(s)

Published by S. Karger AG, Basel karger@karger.com www.karger.com/ore

Karger $\stackrel{\text { ' }}{=}$

BOPEN ACCESS
(C) 2021 The Author(s)

Published by S. Karger AG, Basel

This article is licensed under the Creative Commons Attribution 4.0 International License (CC BY) (http://www.karger.com/Services/ OpenAccessLicense). Usage, derivative works and distribution are permitted provided that proper credit is given to the author and the original publisher.
Correspondence to:

Srilakshmi M. Sharma, publicationqueries@yahoo.com 


\section{Introduction}

Neurofibromatosis type 2 (NF2) is an autosomal dominant single gene disorder which is due to sporadic and inherited pathogenic variants (PVs) of the NF2 gene on chromosome 22. The incidence of NF2 is reported to be as high as 1 in 25,000 individuals in 2 large population studies in Finland and England [1-4]. NF2 is primarily characterized by the development of vestibular schwannomas, as well as other schwannomas, meningiomas, and ependymomas [5].

The NF2 phenotype classically also includes several ocular features such as cataracts and retinal abnormalities: hamartomas of the retina with or without retinal pigment epithelial involvement, and epiretinal membranes (ERMs) [5-10]. Hamartomas are developmental malformations of the retina mainly involving the inner layers, while ERMs in NF2 are proliferations at the vitreoretinal interface seen in spectral domain optical coherence tomography (SD-OCT) as an irregular and hyperreflective layer of the inner limiting membrane [11]. In early studies of NF2, both retinal abnormalities were thought of as distinct entities. Since then, histopathologic studies of eyes from patients with NF2 have shown both abnormalities to predominantly originate from altered retinal Müller cells $[12,13]$. This observation has led some researchers to postulate that some apparent ERMs in NF2 patients are a form of hamartoma [14].

In the past decade, ophthalmic practice has been enhanced by the use of SD-OCT. This is a noncontact diagnostic technique that produces in vivo cross-sectional images of the retina. The SD-OCT technology uses infrared light to render retinal images with very high resolution $(<7 \mu \mathrm{m})$, allowing individual retinal layers and the vitreoretinal interface to be seen [15]. Studies which have used SD-OCT imaging in patients with NF2 have been able to characterize retinal findings in greater detail and identify novel retinal abnormalities such as retinal tufts, which are projections of tissue extending from the inner retina into the vitreous $[14,16,17]$. Retinal tufts are thought to be either focal ERMs or small elevations of retinal tissue which have been termed subclinical hamartomas, due to their small size but have similar histopathologic origin, from glial cells $[12,17]$. While the presence of retinal tufts has been recognized in small case series $[12,17]$, the frequency of retinal tufts in patients with NF2 has not been studied in larger patient groups.

Symptoms and signs relating to vestibular schwannomas are not always the presenting feature in NF2, even less so in children who more commonly manifest eye, skin, or neurological problems [18-21]. The detection of ocular features can aid in the clinical diagnosis of NF2 and prompt early genetic testing $[21,22]$. The recent identification of numerous retinal abnormalities by SDOCT [17], which were previously undetected by fundus photography, suggests that the retinal features of NF2 may be more common than previously thought. They are also more common in more severe NF2 genotypes, an effect captured by a validated genetic severity score for NF2 $[14,17,23-27]$. We set out to systematically characterize the retinal findings in a large cohort of patients with NF2 using SD-OCT and to determine the potential use of this technique as a diagnostic tool in NF2.

\section{Materials and Methods}

\section{Study Design and Patient Selection}

The Oxford University Hospitals NHS Trust is 1 of 4 national centres for the multidisciplinary care of all known patients with NF2 in England. All patients with NF2 within the south-west region of England are under the care of the NF2 service in Oxford.

This case-controlled study compared the SD-OCT findings of all patients with confirmed NF2 according to the Manchester criteria [28-30], who were consecutively seen in the Oxford University Hospitals ophthalmology clinic as part of their annual review between August 2016 and July 2017. Anonymized demographic data were collected, including age, gender, diagnosis, and NF2 genetic severity; the latter was assigned using the UK NF2 genetic severity score dividing the patients into groups: 1 . tissue mosaic; 2A. mild classic; $2 \mathrm{~B}$ moderate classic; and 3. severe [26]. Images of $\mathrm{SD}-\mathrm{OCT}$ s of the eyes from age- and gender-matched healthy volunteers (these had been previously imaged and stored prior to the study, and were taken from a population with no known retinal disease or systemic disorders associated with retinal pathology) were used to serve as the control group.

\section{SD-OCT Imaging}

All patients underwent SD-OCT imaging through undilated pupils using the Spectralis HRA + OCT (Heidelberg Engineering, Heidelberg, Germany). A sequence of horizontal scans recorded in the high-speed mode $\left(768 \mathrm{~A}\right.$-scans $\left./ 30^{\circ}\right)$ and covering an area of $30^{\circ}$ (horizontal) $\times 15^{\circ}$ (vertical) centred on the fovea, with approximately $120 \mu \mathrm{m}$ between individual scans, was recorded.

\section{Image Analysis}

Two masked retinal specialists (SS and PCI) independently analysed SD-OCT scans of NF2 patients and healthy controls in a randomized order. The grey-scale SD-OCT images were viewed on a 22 -inch liquid crystal display monitor $(1,920 \times 1,080$ pixels $)$ using HEYEX software (Heidelberg Engineering).

The assessors were asked to specify the overall appearance of the SD-OCT recordings and the presence or absence of the following qualitative variables: retinal hamartoma, ERM appearance, retinal tufts, and abnormal foveal contour. Examples of these features as demonstrated to the masked assessors (in a single training session) were derived from figures in a previous study of NF2-associ- 
Table 1. Patient demographics

\begin{tabular}{lll}
\hline & NF2 & Control \\
\hline $\begin{array}{lll}\text { Patients, } n \\
\text { Eyes, } n\end{array}$ & 54 & 55 \\
$\begin{array}{l}\text { Age, years } \\
\quad \text { Mean }\end{array}$ & 101 & 110 \\
$\quad \begin{array}{l}\text { Standard deviation } \\
\text { Gender, } n \text { (\%) }\end{array}$ & 37.9 & 37.2 \\
$\quad$ Male & 19 & 15 \\
$\quad$ Female & $26(48.1)$ & $27(49.1)$ \\
$\begin{array}{l}\text { Genetic severity score, } n(\%) \\
\quad \text { tissue mosaic }\end{array}$ & $28(51.9)$ & $28(50.9)$ \\
$\quad \begin{array}{l}\text { 2A mild classic } \\
\text { 2B moderate classic }\end{array}$ & $17(31.5)$ & - \\
$\quad$ 3 severe & $10(18.5)$ & - \\
& $14(25.9)$ & - \\
\end{tabular}

ated retinal tufts [17] as well as previous observations of retinal hamartomas on SD-OCT which appeared as thickening and disorganization of the retinal layers starting from the inner layers and sometimes combining involvement of the retinal pigment epithelium (RPE) - widely known as combined hamartomas of the retina and RPE (CHRRPE) [16].

\section{Exclusion Criteria}

SD-OCT images with a quality of index of $<15$ were excluded (these were patients with NF2 who had nystagmus or media opacities) [31]. Similarly, patients in whom we were unable to obtain an SD-OCT analysis due to physical disabilities were also excluded from the analysis. No images from the control group were excluded.

\section{Statistical Analysis}

SPSS 25 was used for all statistical analyses. We reported summary statistics throughout. Inferential statistical significance was set to $p<0.05$. We calculated the Mantel-Haenszel common odds ratio estimates for each SD-OCT finding with asymptotic $95 \%$ confidence intervals for single strata design comparisons with balanced groups of NF2 and control patients and applied a 0.5 constant continuity correction to all cells in tables with zero events. Trends of increasing proportions of retinal abnormalities with genetic severity, as well as of increasing visual impairment with SDOCT findings, were investigated using Mantel-Haenszel linear-bylinear $\chi^{2}$ tests of association. Associations between SD-OCT abnormalities were investigated using Pearson's $\chi^{2}$ tests and Fisher's exact tests. Multiple comparison corrections were applied.

\section{Results}

There were 63 patients with confirmed NF2 diagnosis of which 9 (11 eyes) were excluded, leaving 54 patients (101 eyes) whose demographics are shown in Table 1. Age- and gender-matched controls $(N=55,110$ eyes $)$ were included for comparison. Case note review of the 54 included patients revealed that $48 \%$ had cataracts $(19 \%$ bilateral), where cataract is a NF2 diagnostic criterion.

Figure 1 shows representative examples of the range and variation in retinal abnormalities observed on SDOCT images of patients with NF2. Most images show isolated retinal tufts appearing as simple small projections above the internal limiting membrane, or larger two-or-more pronged formations often resembling horns or flames. The typical appearance of ERMs as commonly seen in other conditions (a single hyper-reflective sheet seen above the internal limiting membrane, often distorting its shape), was only rarely seen. Retinal hamartomas were seen quite commonly, and involved retinal thickening and disorganization, primarily of the inner layers extending involvement to the RPM in some of the cases.

The ability of SD-OCT to identify tufts that would otherwise likely have been missed on fundus examination is highlighted in Figure 2, where the only sign on the fundus photograph is a slightly abnormal light reflex.

Abnormal SD-OCTs were found in 26 patients with NF2 (48\%) and 2 patients in the control population (4\%) (Table 2). There was perfect inter-observer agreement $(k=1.0)$ between the 2 masked assessors for all retinal abnormalities identified, and therefore, arbitration was not required. The only abnormalities found in the control group were ERMs and abnormal foveal contour; there were no control patients with retinal tufts or retinal hamartomas. Retinal tufts were seen in 23 patients with NF2 (43\%), and retinal hamartomas were seen in 19 patients (35\%). The odds ratio for an abnormal SD-OCT scan in patients with NF2 were significantly higher than those in the control group $(\mathrm{OR}=24.6)$. All odds ratios were statistically significant $(p<0.05)$.

Within this cohort, we found that the presence of an SD-OCT abnormality was associated with at least a $96 \%$ specificity for NF2, although the sensitivity was lower at $48 \%$. The positive predictive value was calculated as $100 \%$ for retinal tufts, supporting their potential as one of the clinical features of NF2. Negative predictive values for SD-OCT abnormalities (53-65\%) indicate that the absence of any SD-OCT abnormalities does not exclude NF2.

Within the NF2 population, retinal tufts were the most frequently encountered abnormality, found in 23 patients (48\%) (Table 3). Retinal hamartomas were seen in 19 patients (35\%), and an abnormal foveal contour was seen in 12 patients (22\%). Eighty-four percent of patients who had retinal hamartoma also had a retinal tuft detected in 

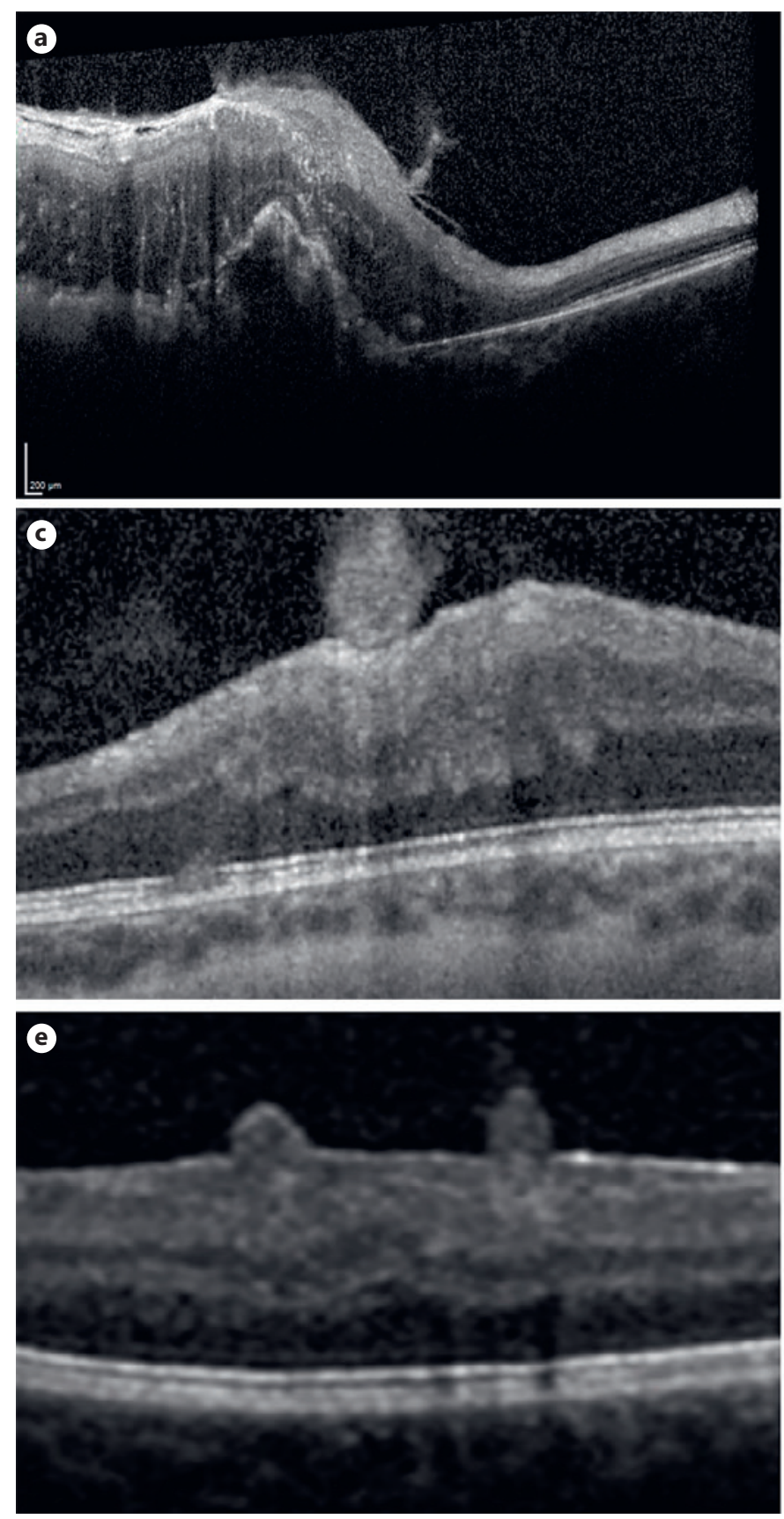

their SD-OCT; $63 \%$ of patients who had retinal hamartoma also had abnormal foveal contour and $26 \%$ had ERMs. ERMs were observed in combination with other retinal tufts and retinal hamartomas $71 \%$ of the time.

When examining the occurrence of multiple retinal abnormalities within the same eye, retinal tufts were found to be the most frequent finding for any combination. Most eyes with an abnormal scan (45\%) had 3 OCT abnormalities, with the most common combination
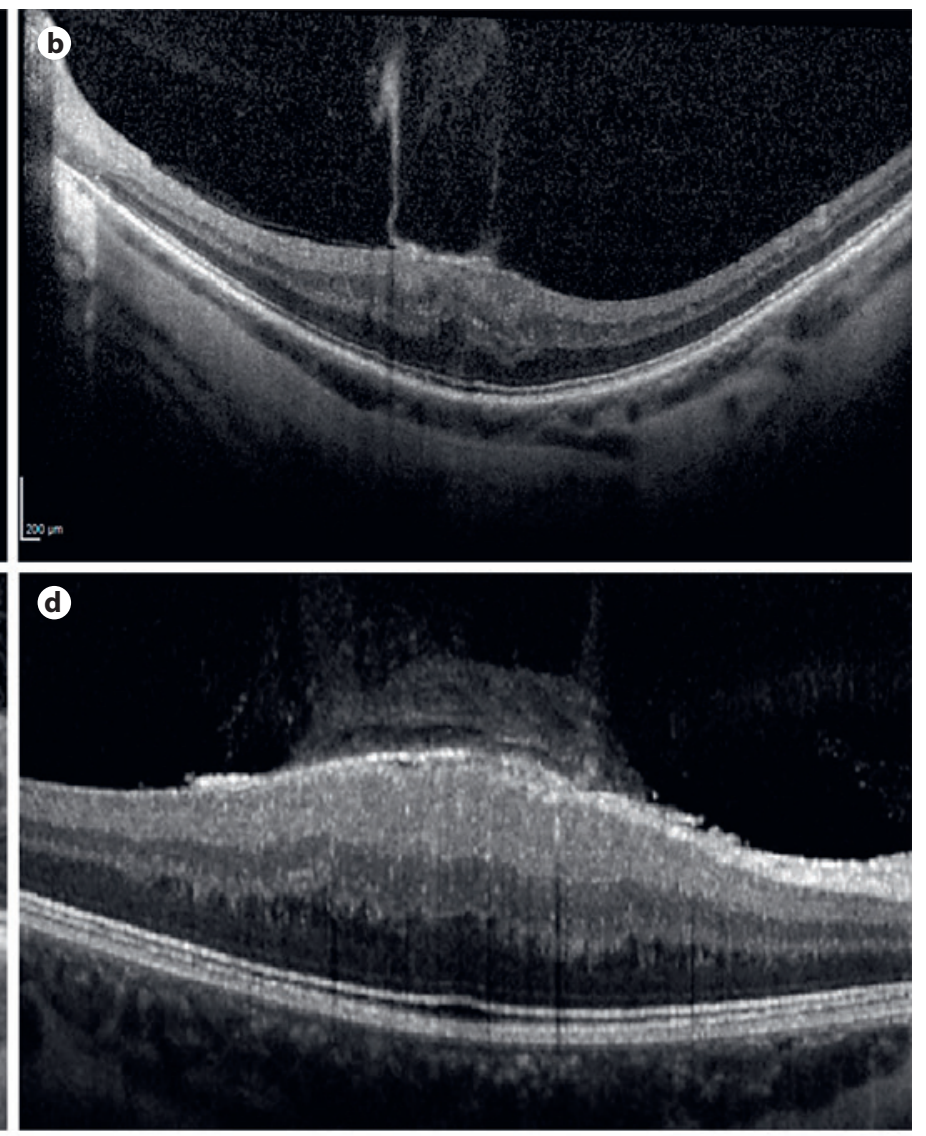

Fig. 1. Examples of SD-OCT images from patients with NF2 illustrating the various retinal abnormalities found. a ERM, combined retinal hamartoma (involving RPE), tuft. b Retinal hamartoma, tuft. c Retinal hamartoma, tuft. d ERM, retinal hamartoma, tuft. e Retinal hamartoma, tuft. SD-OCT, spectral domain optical coherence topography; ERM, epiretinal membrane; RPE, retinal pigment epithelium; NF2, neurofibromatosis type 2.

(39\%) being retinal tufts, retinal hamartoma, and foveal contour. Thirty-nine percent of affected eyes had only 1 abnormality, with the majority (32\%) being retinal tufts. An abnormal foveal contour was always observed in combination with 2 or more other findings.

The relationship between retinal abnormalities and NF2 genetic severity was also examined. Within this cohort, the proportion of patients with retinal tufts, retinal hamartoma, or abnormal foveal contour increased in a
Emmanouil/Wasik/Charbel Issa/Halliday/ Parry/Sharma 

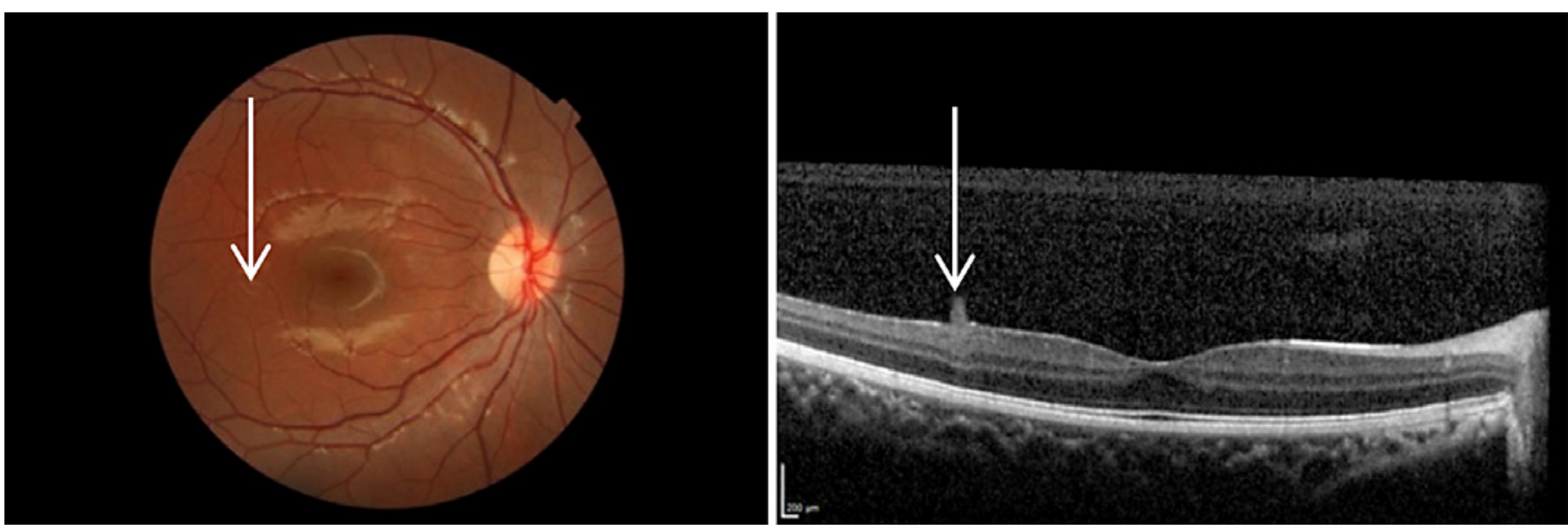

Fig. 2. An illustration of the improved visibility of retinal abnormalities on SD-OCT compared to fundus examination. On the left: fundus colour photograph of a right eye from a NF2 patient. An only mildly abnormal retinal reflex is seen temporal to the fovea (highlighted). On the right: an SD-OCT raster image through the fovea of the eye depicted on the left, showing a small retinal tuft corresponding to the abnormal retinal reflex seen. SDOCT, spectral domain optical coherence topography; NF2, neurofibromatosis type 2.

Table 2. Frequency of SD-OCT abnormalities in patients with NF2 and healthy controls

\begin{tabular}{|c|c|c|c|c|c|c|c|c|c|c|}
\hline \multirow[t]{3}{*}{ SD-OCT finding } & \multicolumn{4}{|c|}{ Group } & \multirow{3}{*}{$\begin{array}{l}\text { Odds } \\
\text { ratio }\end{array}$} & \multirow[t]{3}{*}{$95 \% \mathrm{Cl}$} & \multirow{3}{*}{$\begin{array}{l}\text { Sensitivity, } \\
\%\end{array}$} & \multirow{3}{*}{$\begin{array}{l}\text { Specificity, } \\
\%\end{array}$} & \multirow{3}{*}{$\begin{array}{l}\text { Positive } \\
\text { predictive } \\
\text { value, } \%\end{array}$} & \multirow{3}{*}{$\begin{array}{l}\text { Negative } \\
\text { predictive } \\
\text { value, } \%\end{array}$} \\
\hline & \multicolumn{2}{|c|}{$\begin{array}{l}\text { NF2 patients, } \\
(N=54)\end{array}$} & \multicolumn{2}{|c|}{$\begin{array}{l}\text { control group, } \\
(N=55)\end{array}$} & & & & & & \\
\hline & $N$ & $\%$ & $N$ & $\%$ & & & & & & \\
\hline Abnormal scan & 26 & 48 & 2 & 4 & 24.6 & $(5.4,111.3)$ & 48 & 96 & 93 & 65 \\
\hline Retinal tuft & 23 & 43 & 0 & 0 & 82.8 & $(4.9,1,410.4)$ & 43 & 100 & 100 & 64 \\
\hline Retinal hamartoma & 19 & 35 & 0 & 0 & 61.0 & $(3.6,1,042.1)$ & 35 & 100 & 100 & 61 \\
\hline Abnormal foveal contour & 12 & 22 & 2 & 4 & 7.6 & $(1.6,35.7)$ & 22 & 96 & 86 & 56 \\
\hline ERM & 7 & 13 & 2 & 4 & 3.9 & $(0.8,19.9)$ & 13 & 96 & 78 & 53 \\
\hline
\end{tabular}

Odd ratios (with 95\% confidence intervals) for each SD-OCT qualitative variable in NF2 are shown, as well as the specificity, sensitivity, positive predictive value, and negative predictive value of each abnormality. ERM, epiretinal mebrane; $N$, number of patients; SD-OCT, spectral domain optical coherence topography; NF2, neurofibromatosis type 2.

Table 3. Associations between retinal abnormalities in patients with NF2 demonstrating the frequency of retinal tufts in association with other abnormalities in patients with NF2

\begin{tabular}{lllll}
\hline & $\begin{array}{l}\text { Retinal tuft, } \\
n(\%)\end{array}$ & $\begin{array}{l}\text { Retinal } \\
\text { hamartoma, } n(\%)\end{array}$ & $\begin{array}{l}\text { Abnormal foveal } \\
\text { contour, } n(\%)\end{array}$ & $\begin{array}{l}\text { ERM, } \\
n(\%)\end{array}$ \\
\hline Total patients $(N=54)$ & $23(43)$ & $19(35)$ & $12(22)$ & $7(13)$ \\
\hline $\begin{array}{l}\text { Retinal tuft } \\
(N=23)(17 \text { bilateral) }\end{array}$ & $\mathrm{N} / \mathrm{A}$ & $16(84)^{* *}$ & $12(100)^{* *}$ & $5(71)$ \\
\hline $\begin{array}{l}\text { Retinal hamartoma } \\
(N=19)(9 \text { bilateral) }\end{array}$ & $16(70)^{* *}$ & $\mathrm{~N} / \mathrm{A}$ & $12(100)^{* *}$ & $5(71)$ \\
\hline $\begin{array}{l}\text { Abnormal foveal contour } \\
(N=12)(6 \text { bilateral) }\end{array}$ & $12(52)^{* *}$ & $12(63)^{* *}$ & $\mathrm{~N} / \mathrm{A}$ & $1(14)$ \\
\hline ERM $(N=7)(0$ bilateral) & $5(22)$ & $5(26)$ & $1(8)$ & $\mathrm{N} / \mathrm{A}$ \\
\hline
\end{tabular}

ERM, epiretinal mebrane appearance; $N$, number of patients; NF2, neurofibromatosis type $2 .{ }^{* *}$ Indicates a statistically significant association $(p<0.01)$.
Central Retinal Abnormalities in

Neurofibromatosis Type 2
Ophthalmic Res 2022;65:77-85

DOI: $10.1159 / 000519143$ 
Fig. 3. Percentage of patients within each NF2 genetic severity group with specific retinal abnormalities. NF2 genetic severity comprises 4 groups: 1 . tissue mosaic, 2A. mild classic, 2B. moderate classic, and 3. severe. NF2, neurofibromatosis type 2 .

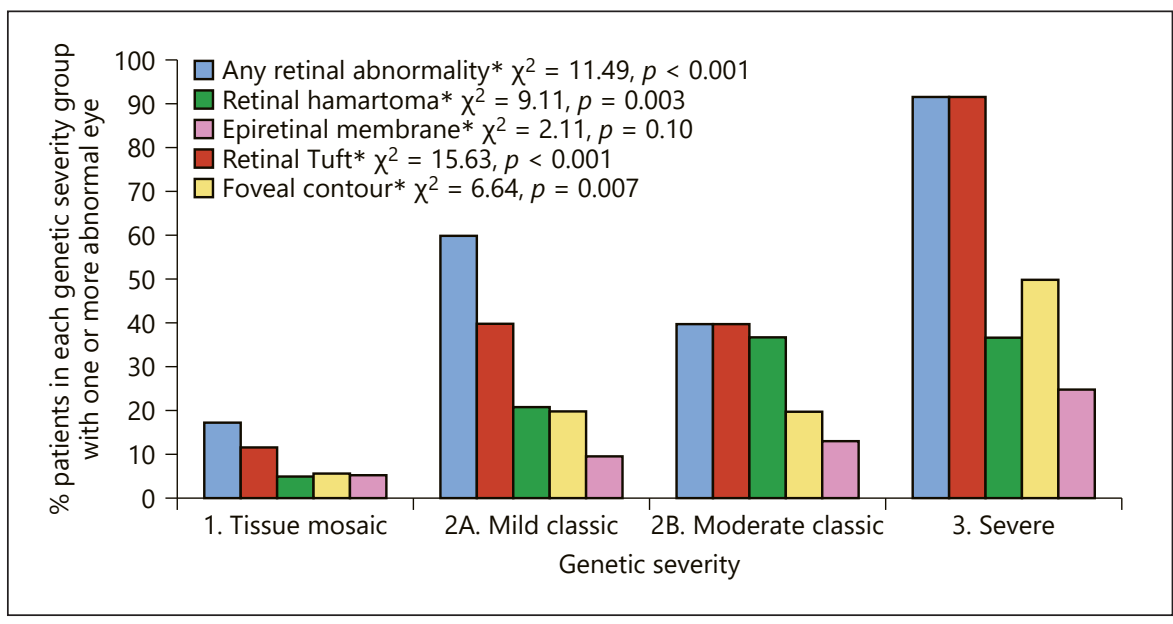

statistically significantly manner with genetic severity. All patients within the severe NF2 genetic severity (group 3) had an abnormal SD-OCT; 7 of 14 patients $(50 \%)$ in group 2B, 6 of $10(60 \%)$ in group $2 \mathrm{~A}$, and 3 of 17 patients (18\%) in group 1 had abnormal SD-OCTs (Fig. 3). ERM prevalence in NF2 was comparable across all genetic severity groups in this cohort. The variability in phenotype is reflected in the lower negative predictive values, as absence of retinal abnormalities in the milder genotype groups does not exclude NF2.

\section{Discussion/Conclusion}

Early diagnosis of NF2 is important to optimize management and allow timely intervention. The diagnosis of NF2 is frequently delayed [32], especially in children with severe de novo NF2, who typically present with symptoms and signs that are not related to a vestibular schwannoma [18-21]. The heterogeneous presenting clinical features of NF2 highlight the value in developing reliable biomarkers for NF2.

SD-OCT scans are noninvasive, rapidly acquired images capable of diagnosing and monitoring many retinal disorders, and are routinely performed in the community and in the hospital setting. For patients with NF2, it enables abnormalities within each retinal layer to be phenotyped with great accuracy. Retinal tufts may easily be missed on funduscopic examination or colour photography (Fig. 1) and were the most frequently occurring OCTbased retinal abnormality in this large NF2 cohort ( $43 \%$ NF2; $0 \%$ controls). In fact, it was rare to find an abnormal SD-OCT that did not include a retinal tuft (12\% of abnormal scans). An inter-observer agreement of $100 \%$ be- tween the 2 OCT-assessing ophthalmologists demonstrated the ease and accuracy of identification of retinal tufts.

Retinal tufts within NF2 are small, isolated proliferations of the glial tissue (focal ERMs) or discrete elevations of inner retinal tissues $[12,13]$. The term "retinal tuft" has been used elsewhere to describe idiopathic peripheral cystic lesions whose morphology as seen on OCT is not dissimilar to the retinal tufts seen in NF2 [33]. However, to our knowledge, they have never been described within the macula region as retinal tufts but rather as probable astrocytic hamartomas [34]. The term, retinal tufts has been used for lesions in the far periphery of the retina [35].

We characterized the central retinal pathology in NF2 using SD-OCT imaging characteristics only, resulting in a number of differences from previous reports based upon clinical examination $[7,8,14]$. For example, ERMs were an infrequent finding in our study (13\%), compared with previous fundus examinations on patients reported by Meyers et al. [8], where 12 of 15 patients had ERMs. It is likely that the patients reported in Meyers et al. [8] were of a more severe genotype. Other SD-OCT NF2 studies have classified SD-OCT findings in NF2 as either ERMs or retinal hamartomas while we have reported various anatomical changes of which the retinal tuft is 1 descriptor.

In our study, as well as in previous, retinal hamartomas were associated with more severe disease in NF2 $[8,10$, $24,32]$. Of the 8 patients with CHRRPE, none belonged to the 1 . tissue mosaic group and 5 of the $302 \mathrm{~B}$. moderate classic patients had a combined hamartoma. Also, there was no significant difference in the ages of the patients whose hamartoma involved the RPE and those whose
Emmanouil/Wasik/Charbel Issa/Halliday/ Parry/Sharma 
hamartoma was limited in the inner layers. While CHRRPEs have been seen with NF2 in some studies [8, $16,22]$, in others - especially involving larger groups of patients - retinal hamartomas were observed to have none, occasional, or very mild RPE involvement $[10,12$, $16,23,24]$. This is in line with our findings that suggest that a smaller proportion of retinal hamartomas observed using SD-OCT in NF2 are CHRRPEs. Of the 8 patients who had CHRRPE 1 also had an ERM. Only 1 of 7 ERMs was observed with a CHRRPE but $71 \%$ with a retinal hamartoma that did not involve the RPE, which is in line with previous observations of retinal hamartomas with ERMs [16, 24].

Tuberous sclerosis, among other phakomatoses, also causes subtle retinal hamartomas not seen in fundus examination [36]. However, their morphology is different from that observed in NF2. Other isolated abnormalities of astrocytic proliferation that we have identified in the literature as being similar to the retinal tufts in our study are still quite distinct and easily differentiated [37]. Astrocytic proliferations are more discrete, more raised, and the shadowing on OCT that they produce obscures the retinal layers in a way that tufts seen within our study do not. Frequent bilateral involvement has also been associated with NF2 $[9,38]$, and this has been confirmed herein.

Although our sample size was small (54 patients and 55 controls), these preliminary data suggest that retinal tufts have a higher sensitivity in NF2 than any other ocular feature herein. Fourty-eight percent (30\% unilateral) of patients in this dataset had cataracts, a current diagnostic criterion, comparable to $43 \%$ with retinal tufts, emphasising the importance of this retinal abnormality in NF2 diagnosis. Twenty-eight percent of patients with NF2 had both cataracts and retinal tufts, but only $5 \%$ had bilateral cataracts and bilateral retinal tufts. Our data show that the probability of an individual with a retinal tuft or retinal hamartoma having NF2 was $100 \%$; however, this is an overestimate as retinal hamartomas have also been observed in other rare diseases $[7,8,22,27$, $38-44]$. An appropriately powered control group including other ophthalmic diseases will be required to unequivocally establish sensitivity and specificity of retinal tufts.

The presence of retinal tufts is not uniformly distributed among patients and is particularly indicative of a severe genotype; expression increases with higher NF2 genetic severity scores, occurring with a $12 \%$ frequency in group 1 tissue mosaic patients where there are no NF2 PVs in the blood and 100\% frequency in group 3 severe

Central Retinal Abnormalities in

Neurofibromatosis Type 2 patients where there are truncating constitutional NF2 PVs. Although a negative result may not exclude NF2, detection of retinal tufts may be especially important in children with non-specific signs, such as amblyopia or a cranial nerve palsy. We have previously found that ophthalmological findings are the most frequent first manifestations in paediatric onset NF2 [19]. In the manner that detection of retinal hamartoma in children may lead to a diagnosis of NF2 [22], retinal tufts may indicate evaluation for NF2 in a specialist clinic. NF2 can be diagnosed with a variety of combinations of clinical features and the current guidelines recommend follow-up for patients with probable NF2 until diagnosis is possible or discharge after a certain age when risk falls below $1 \%$ [45]. The presence of retinal tufts, if validated, may merit inclusion as a diagnostic criterion. The identification of a structural abnormality on SD-OCT and in particular retinal tufts in asymptomatic offspring of would suggest that a child had inherited NF2 and may allow earlier diagnosis in cases where presymptomatic genetic testing is not possible. Furthermore, as all patients in group 3. severe had retinal tufts, a normal SD-OCT may reduce the likelihood that a child had inherited a severe NF2 [16]. However, we acknowledge that the natural history of retinal tuft development in the context of NF2 is not yet known.

Limitations in this study include the low sample size due to the rarity of NF2. However, the magnitude of difference between NF2 and control groups affirms the validity of the findings of this study, which is the largest OCT series reported in the NF2 population to date. A larger control group and comparison with other associated disorders such as schwannomatosis or NF1 will be necessary to accurately define the diagnostic value of retinal tufts. Media opacities within the eye such as dense cataracts and corneal scarring or oculomotility disorders such as nystagmus hamper the feasibility of OCT imaging, making it unsuitable for a small proportion of patients, potentially leading to an underestimate of retinal findings since poor vision is usually associated with worse genetic severity [14, 17, 23-27]. We only obtained SDOCT scans through the macula; while the majority of studies in NF2 report retinal abnormalities predominantly in the macula region, there are reports of retinal hamartomas in the peripheral retina in patients with NF2 [8, 46], which would not have been detected in our study potentially further underestimating the frequency of retinal abnormalities in this patient group. Furthermore, scanning the central retinal only could potentially miss other structures in the extramacular retina such as vitreoretinal bands or posterior vitreous remnants which might 
be seen in non-NF2 populations. Wide-field retinal SDOCT may be valuable in the evaluation of retinal findings in NF2 [47].

In summary, we present the largest SD-OCT study to date, to detect retinal abnormalities in NF2. Our results indicate a high frequency of retinal abnormalities, readily detected by SD-OCT. We propose that using SD-OCT, rather than fundus photography, will allow accurate phenotyping of retinal abnormalities in NF2, and with less ambiguity than with clinical examination alone. This may have particular benefit in avoiding delayed diagnosis in children. Retinal tufts at the macula appear to be rapidly identifiable, common features of NF2, with high specificity, suggesting a possible role for this feature as a novel diagnostic marker of NF2.

\section{Acknowledgements}

The authors would like to thank the patients and the NF2 team. In particular, they would like to thank Rosie Crabtree, Carolyn Redman, Gillian Hemmings, Wendy Howard, Monisha Rahman, Youssef Sida, Kate Browne, and Rachel Woolrich.

\section{Statement of Ethics}

The study was approved and registered as a service evaluation (ref: 091216-NOTSS-ASLAM) at Oxford University Hospitals NHS Foundation Trust, and all procedures undertaken in the study were in accordance with the 1964 Helsinki Declaration. As there was no active human participation in this study (this is a retrospective, anonymized review of routinely collected clinical data), no informed consent was deemed necessary by the health research authority. Ethical approval was not sought because clinical audits in UK are subject to different guidance in accordance with the National Research Ethics Service (2009), thus exempting the work from the need for ethical approval [48].

\section{Conflict of Interest Statement}

The authors have no conflicts of interest to declare.

\section{Funding Sources}

Financial support: PCI was supported by the National Institute for Health Research (NIHR) Oxford Biomedical Research Centre (BRC), Oxford, United Kingdom; SMS receives funding from MRC UK (Grant No.: MR/T024682/1).

\section{Author Contributions}

B.E. substantially contributed to the design of the work, the acquisition, analysis, and interpretation of data for the work as well as the drafting of the work and revision for critically important intellectual content; M.W. substantially contributed to the concept and design of the work, the acquisition, and interpretation of data for the work as well as the drafting of the work; P.C.I. substantially contributed to the acquisition and interpretation of data for the work as well as the revision for critically important intellectual content; D.H. substantially contributed to the design of the work, the interpretation of data for the work as well as the revision for critically important intellectual content; A.P. substantially contributed to the design of the work, the interpretation of data for the work as well as the revision for critically important intellectual content; S.M.S. substantially contributed to the design of the work, the interpretation of data for the work as well as revision for critically important intellectual content. All authors gave final approval of the version to be published and agreed to be accountable for all aspects of the work in ensuring that questions related to the accuracy or integrity of any part of the work are appropriately investigated and resolved.

\section{Data Availability Statement}

We cannot share any raw anonymized data due to the small numbers of patients in our study and the rarity of the disease. We will consider requests for aggregate data on an individual basis.

\section{References}

1 Evans DG, Howard E, Giblin C, Clancy T, Spencer H, Huson SM, et al. Birth incidence and prevalence of tumor-prone syndromes: estimates from a UK family genetic register service. Am J Med Genet A. 2010;152A(2): $327-32$.

2 Evans DG, Bowers NL, Tobi S, Hartley C, Wallace AJ, King AT, et al. Schwannomatosis: a genetic and epidemiological study. J Neurol Neurosurg Psychiatry. 2018;89(11):1215-9.

3 Antinheimo J, Sankila R, Carpén O, Pukkala E, Sainio M, Jääskeläinen J. Population-based analysis of sporadic and type 2 neurofibromatosis-associated meningiomas and schwannomas. Neurology. 2000;54(1):71-6.
4 Evans DG, Moran A, King A, Saeed S, Gurushinghe N, Ramsden R. Incidence of vestibular schwannoma and neurofibromatosis 2 in the north west of England over a 10-year period: higher incidence than previously thought. Otol Neurotol. 2005;26(1):93-7.

5 Evans DG, Huson SM, Donnai D, Neary W, Blair V, Newton V, et al. A clinical study of type 2 neurofibromatosis. Q J Med. 1992; 84(304):603-18.

6 Bosch MM, Boltshauser E, Harpes P, Landau K. Ophthalmologic findings and long-term course in patients with neurofibromatosis type 2. Am J Ophthalmol. 2006;141(6):106877.
7 Kaye LD, Rothner AD, Beauchamp GR, Meyers SM, Estes ML. Ocular findings associated with neurofibromatosis type II. Ophthalmology. 1992;99(9):1424-9.

8 Meyers SM, Gutman FA, Kaye LD, Rothner AD. Retinal changes associated with neurofibromatosis 2. Trans Am Ophthalmol Soc. 1995;93:245-7; discussion 52-7.

9 Landau K, Yaşargil GM. Ocular fundus in neurofibromatosis type 2 . Br J Ophthalmol. 1993;77(10):646-9.

10 Ragge NK, Baser ME, Klein J, Nechiporuk A, Sainz J, Pulst SM, et al. Ocular abnormalities in neurofibromatosis 2. Am J Ophthalmol. 1995;120(5):634-41. 
11 Hubschman JP, Govetto A, Spaide RF, Schumann R, Steel D, Figueroa MS, et al. Optical coherence tomography-based consensus definition for lamellar macular hole. $\mathrm{Br} \mathrm{J}$ Ophthalmol. 2020;104(12):1741-7.

12 Chan CC, Koch CA, Kaiser-Kupfer MI, Parry DM, Gutmann DH, Zhuang Z, et al. Loss of heterozygosity for the NF2 gene in retinal and optic nerve lesions of patients with neurofibromatosis 2. J Pathol. 2002;198(1):14-20.

13 McLaughlin ME, Pepin SM, Maccollin M, Choopong P, Lessell S. Ocular pathologic findings of neurofibromatosis type 2. Arch Ophthalmol. 2007;125(3):389-94.

14 Sisk RA, Berrocal AM, Schefler AC, Dubovy SR, Bauer MS. Epiretinal membranes indicate a severe phenotype of neurofibromatosis type 2. Retina. 2010;30(4 Suppl):S51-8.

15 Nassif N, Cense B, Park B, Pierce M, Yun S, Bouma $B$, et al. In vivo high-resolution videorate spectral-domain optical coherence tomography of the human retina and optic nerve. Opt Express. 2004;12(3):367-76.

16 Kang HM, Koh HJ, Chung EJ. Spectral-domain optical coherence tomography of combined hamartoma of the retina and retinal pigment epithelium in neurofibromatosis. Korean J Ophthalmol. 2013;27(1):68-71.

17 Waisberg V, Rodrigues LO, Nehemy MB, Frasson M, de Miranda DM. Spectral-domain optical coherence tomography findings in neurofibromatosis type 2. Invest Ophthalmol Vis Sci. 2016;57(9):OCT262-7.

18 Ruggieri M, Iannetti P, Polizzi A, La Mantia I, Spalice A, Giliberto O, et al. Earliest clinical manifestations and natural history of neurofibromatosis type 2 (NF2) in childhood: a study of 24 patients. Neuropediatrics. 2005; 36(1):21-34.

19 Halliday D, Emmanouil B, Vassallo G, Lascelles K, Nicholson J, Chandratre S, et al. Trends in phenotype in the English paediatric neurofibromatosis type 2 cohort stratified by genetic severity. Clin Genet. 2019;96(2):15162.

20 Ruggieri M, Praticò AD, Serra A, Maiolino L, Cocuzza S, Di Mauro P, et al. Childhood neurofibromatosis type 2 (NF2) and related disorders: from bench to bedside and biologically targeted therapies. Acta Otorhinolaryngol Ital. 2016;36(5):345-67.

21 Anand G, Vasallo G, Spanou M, Thomas S, Pike M, Kariyawasam DS, et al. Diagnosis of sporadic neurofibromatosis type 2 in the paediatric population. Arch Dis Child. 2018; 103(5):463-9.

22 Grant EA, Trzupek KM, Reiss J, Crow K, Messiaen L, Weleber RG. Combined retinal hamartomas leading to the diagnosis of neurofibromatosis type 2. Ophthalmic Genet. 2008; 29(3):133-8.

23 Baser ME, Kluwe L, Mautner VF. Germ-line NF2 mutations and disease severity in neurofibromatosis type 2 patients with retinal ab- normalities. Am J Hum Genet. 1999;64(4): 1230-3.

24 Parry DM, MacCollin MM, Kaiser-Kupfer MI, Pulaski K, Nicholson HS, Bolesta M, et al. Germ-line mutations in the neurofibromatosis 2 gene: correlations with disease severity and retinal abnormalities. Am J Hum Genet. 1996;59(3):529-39.

25 Feucht M, Kluwe L, Mautner VF, Richard G. Correlation of nonsense and frameshift mutations with severity of retinal abnormalities in neurofibromatosis 2. Arch Ophthalmol. 2008; 126(10):1376-80.

26 Halliday D, Emmanouil B, Pretorius P, MacKeith S, Painter S, Tomkins H, et al. Genetic severity score predicts clinical phenotype in NF2. J Med Genet. 2017;54(10):65764.

27 Painter S, Sipkova Z, Emmanouil B, Halliday D, Parry A, Elston J. Neurofibromatosis type 2-related eye disease correlated with genetic severity type. J Neuroophthalmol. 2019;39(1): 44-9.

28 Smith MJ, Bowers NL, Bulman M, Gokhale C, Wallace AJ, King AT, et al. Revisiting neurofibromatosis type 2 diagnostic criteria to exclude LZTR1-related schwannomatosis. Neurology. 2017;88(1):87-92.

29 Gutmann DH, Aylsworth A, Carey JC, Korf B, Marks J, Pyeritz RE, et al. The diagnostic evaluation and multidisciplinary management of neurofibromatosis 1 and neurofibromatosis 2. JAMA. 1997;278(1):51-7.

30 Evans DG, Huson SM, Donnai D, Neary W, Blair V, Newton V, et al. A genetic study of type 2 neurofibromatosis in the United Kingdom. II. Guidelines for genetic counselling. J Med Genet. 1992;29(12):847-52.

31 Huang Y, Gangaputra S, Lee KE, Narkar AR, Klein R, Klein BE, et al. Signal quality assessment of retinal optical coherence tomography images. Invest Ophthalmol Vis Sci. 2012; 53(4):2133-41.

32 Parry DM, Eldridge R, Kaiser-Kupfer MI, Bouzas EA, Pikus A, Patronas N. Neurofibromatosis 2 (NF2): clinical characteristics of 63 affected individuals and clinical evidence for heterogeneity. Am J Med Genet. 1994;52(4): 450-61.

33 Taney LS, Baumal CR. Optical coherence tomography of a cystic retinal tuft. JAMA Ophthalmol. 2014;132(10):1191.

34 Starosta DA, Lorenz B. [Retinal astrocytic hamartoma in neurofibromatosis type 2 metaanalysis and a case report]. Klin Monbl Augenheilkd. 2018;235(3):290-300.

35 Choudhry N, Golding J, Manry MW, Rao RC. Ultra-widefield steering-based spectral-domain optical coherence tomography imaging of the retinal periphery. Ophthalmology. 2016;123(6):1368-74.

36 Xu L, Burke TR, Greenberg JP, Mahajan VB, Tsang SH. Infrared imaging and optical coherence tomography reveal early-stage astro- cytic hamartomas not detectable by fundoscopy. Am J Ophthalmol. 2012;153(5):883-9. e2.

37 Shields CL, Manalac J, Das C, Saktanasate J, Shields JA. Review of spectral domain-enhanced depth imaging optical coherence tomography of tumors of the retina and retinal pigment epithelium in children and adults. Indian J Ophthalmol. 2015;63(2):128-32.

38 Dedania VS, Ozgonul C, Zacks DN, Besirli CG. Novel classification system for combined hamartoma of the retina and retinal pigment epithelium. Retina. 2018;38(1):12-9.

39 Destro M, D'Amico DJ, Gragoudas ES, Brockhurst RJ, Pinnolis MK, Albert DM, et al. Retinal manifestations of neurofibromatosis. Diagnosis and management. Arch Ophthalmol. 1991;109(5):662-6.

40 Arepalli S, Pellegrini M, Ferenczy SR, Shields CL. Combined hamartoma of the retina and retinal pigment epithelium: findings on enhanced depth imaging optical coherence tomography in eight eyes. Retina. 2014;34(11): 2202-7.

41 De Potter P, Stanescu D, Caspers-Velu L, Hofmans A. Photo essay: combined hamartoma of the retina and retinal pigment epithelium in Gorlin syndrome. Arch Ophthalmol. 2000;118(7):1004-5.

42 Demirci H, Shields CL, Shields JA. New ophthalmic manifestations of branchio-oculo-facial syndrome. Am J Ophthalmol. 2005; 139(2):362-4.

43 Stupp T, Pavlidis M, Bochner T, Thanos S. Poland anomaly associated with ipsilateral combined hamartoma of retina and retinal pigment epithelium. Eye. 2004;18(5):5502.

44 Vianna RN, Pacheco DF, Vasconcelos MM, de Laey JJ. Combined hamartoma of the retina and retinal pigment epithelium associated with neurofibromatosis type-1. Int Ophthalmol. 2001;24(2):63-6.

45 Evans DG, Raymond FL, Barwell JG, Halliday D. Genetic testing and screening of individuals at risk of NF2. Clin Genet. 2012;82(5):41624.

46 Bouzas EA, Parry DM, Eldridge R, KaiserKupfer MI. Familial occurrence of combined pigment epithelial and retinal hamartomas associated with neurofibromatosis 2 . Retina. 1992;12(2):103-7.

47 Polans J, Keller B, Carrasco-Zevallos OM, LaRocca F, Cole E, Whitson HE, et al. Widefield retinal optical coherence tomography with wavefront sensorless adaptive optics for enhanced imaging of targeted regions. Biomed Opt Express. 2017;8(1):16-37.

48 NHS Health Research Authority. Is my study research? Defining research: NRES guidance to help you decide if your research requires review by a research ethics committee. 2009. Available from: http://www.hradecisiontools. org.uk/research/.
Central Retinal Abnormalities in

Neurofibromatosis Type 2
Ophthalmic Res 2022;65:77-85

DOI: $10.1159 / 000519143$ 